\title{
Household changes in contemporary China: an analysis based on the four recent censuses
}

\author{
Zhan $\mathrm{Hu}^{1,2}$ and Xizhe Peng ${ }^{2 *}$
}

\author{
* Correspondence: \\ xzpeng@fudan.edu.cn \\ ${ }^{2}$ Center for Population and \\ Development Policy, Fudan \\ University, Shanghai, China \\ Full list of author information is \\ available at the end of the article
}

\begin{abstract}
This paper analyzed China's household changes based on data from China's past four censuses of 1982, 1990, 2000, and 2010. The data showed that there was a rapid increase in the number of family households, a continued shrinking in household size, and a trend of simplification in household structure. The proportions of the one-couple household and the two-generation standard nuclear household presented the largest rise and the largest fall, respectively. Although the nuclear household still occupied the largest proportion, the single-person household was becoming more numerous, and the extended-family household still maintained a relatively large proportion. Low fertility, population mobility, aging, and the improvement of housing conditions were among the most significant factors that brought about changes to the family and the household in China. In addition, with the population aging, families with elderly members and empty-nest families progressively increased. While the proportion of the elderly-only family households increased, the share of coresidence of old people living with children declined. In China, the elderly are adopting two major forms of living arrangements: living alone or in multigeneration families. Future family policy should pay more attention to this phenomenon.
\end{abstract}

\section{Background}

Since the era of reform and opening-up, profound social and economic transformation has made a persistent impact on China's population growth. The Chinese government also directly intervenes in family activities through the making and implementation of family planning policy and has become a major force in China's household changes. Against this background, the size, structure, and stability of China's household have gone through significant transformation. The function of the family and its ability to bear traditional responsibility have been challenged to a greater or lesser extent. Most significantly, the large number of one-child families puts great pressure on the traditional family support system for elderly care. What are the specific changes that have taken place in contemporary Chinese families?

In the past 10 years, empirical and theoretical research on household changes has been rather active. For example, by exploring the three censuses between 1982 and 2000, Zeng Yi and Wang Zhenglian (2005) discover that by 2000 the percentage of three-generation families increased while the percentage of two-generation nuclear families dropped significantly. However, they argue that this finding should not be interpreted as a return to tradition but is in fact a lag effect of the decrease in the birth rate since the 1970s. Based 
mainly on the 2000 census and by comparing data across each census, Wang Yuesheng (2006) suggests three new types of households in China: the relatively stable type (e.g., three-generation immediate family), the obviously increasing type (e.g., single-person household, one-couple household, generation-skipping household), and the decreasing type (e.g., impaired nuclear family). By analyzing data from the 2005 "minicensus," Guo Zhigang (2008) argues that the family planning policy is the important factor behind the shrinking of family size, yet its impact has been weakening since 1990. At the same time, he points out that although sharing a residence with their offspring is still the elderly's main habitation mode, the "empty-nest" elderly family has become increasingly prevalent. Through exploring the data from a sampling survey in five cities, Feng Xiaotian (2009) concludes that the marriage of the only child in the family is the main reason for the change in parents' household structure. Ma Chunhua et al. (2011) conducted research in Guangzhou, Hangzhou, Zhengzhou, Lanzhou, and Ha'erbin in 2008. The findings of their research confirm the dominance of the nuclear family in China. From the perspective of social gender, their analysis demonstrates the complexity of the changes in Chinese households, which, according to the authors, is "a game between tradition and modernity." Tang Can (2012) carried out a series of research work on urban family relationships and challenges the argument that the Chinese model of elderly care is based on exchange. On the other hand, Yang Shanhua (2011b) puts great emphasis on the macro background of China's social transformation, based on which he carries out theoretical discussion.

In fact, it is an extremely difficult task to present an all-encompassing analysis of family transformation. On the one hand, the connotation and extended meaning of the term "family" differ in different languages. As early as the 1930s, Fei Xiaotong pointed out the difference in meaning of "family" in English and Chinese. He therefore specifically uses the term "expanded family" as the translation for the Chinese word "family" (Fei, 1933). The meaning of the term family concerns not only marriage but also parenthood and intergenerational relationships, if not more so. However, quantitative data used in family research is lacking. Although the family relationship is based on marriage and kinship, it can be separated geographically. Thus, the difficulty in determining the subject of study makes it hard to collect data and may lead to errors. For practical reasons, the household has been used as the substitute or approximate for family. China's censuses provide abundant data for household research, and many outstanding studies have been carried out as a result. Yet, most such research is based on data from the 2000 census and 2005 "minicensus," which fails to reflect the latest changes in Chinese households. This article is based on the analysis of data from the sixth census in 2010. Compared to the data from past censuses between 1982 and 2000, this paper discusses the trend of transformation with regard to Chinese households.

In the Chinese census, the household is defined in this way: "persons who are related as family members (or others), residing and living together, constitute a household; person who lives by him/herself also constitutes a household." This paper mainly draws on data related to household information from the $1 \%$ sampling database of the sixth census (2010) long form, as well as sampling data from the 1982, 1990, and 2000 censuses and the 2010 Shanghai census. It is worth mentioning that based on the relatively large shrinkage of population in the 0-year-old cohort, this census is still haunted by the "curse" of "concealed births in the census year" (Zhu Qin, 2012). Unlike the principle of "permanent residence" registration adopted in the fifth census, the sixth census followed a registration 
principle that collects data on both the "current residence" and "permanent residence." The floating population must be registered at both the current address and the permanent address. Thus, the sixth census is more effective in avoiding missing registration (Chen Wei and Yang Shenghui, 2011), yet this adds to the risk of duplicated registration. The sixth Census office at the State Department and the National Bureau of Statistics reveal the missing registration rate to be at a relatively low level, $0.12 \%$, based on a qualitytesting sampling survey conducted afterward (2011). The quality testing of the data from the sixth census is still certainly in need of support from more basic data and methods and requires further research. This paper is not concerned with the inherited errors of the census data but to avoid the effect of possible errors. The data used in the analysis is mainly relative numbers instead of absolute numbers.

\section{Basic facts on the changes in Chinese households}

\section{Households increase faster than population growth}

Data from the sixth census shows that by 2010, China's household population totalled 1.245 billion, accounting for $93 \%$ of the total population. There were 0.402 billion households, which represents $96.2 \%$ of China's total households (the remaining $3.8 \%$ are collective households). There were 61.44 million more households in 2010. The number of households grew by $18.1 \%$, with an average annual growth rate of $1.7 \%$, a far greater rate than that of population growth (see Fig. 1). Given this trend, Chinese households will continue to grow and are estimated to reach 0.5 billion by 2035-2040. After reaching the peak in 2043-2048, it will then decrease slightly.

Household size continues to decrease; half of total households contain two to three people Due to changes in the total population, age structure, population quality, and rural-urban structure, household size has continued to decrease over the past 30 years. During the fourth census in 1982, households of four to five persons were most prevalent, while households of six and more persons accounted for $28 \%$ of total households. Yet in 19992000, large households were no longer typical. From 2000 onward, households of three persons were the most common type. The percentage of one-to-three-person households

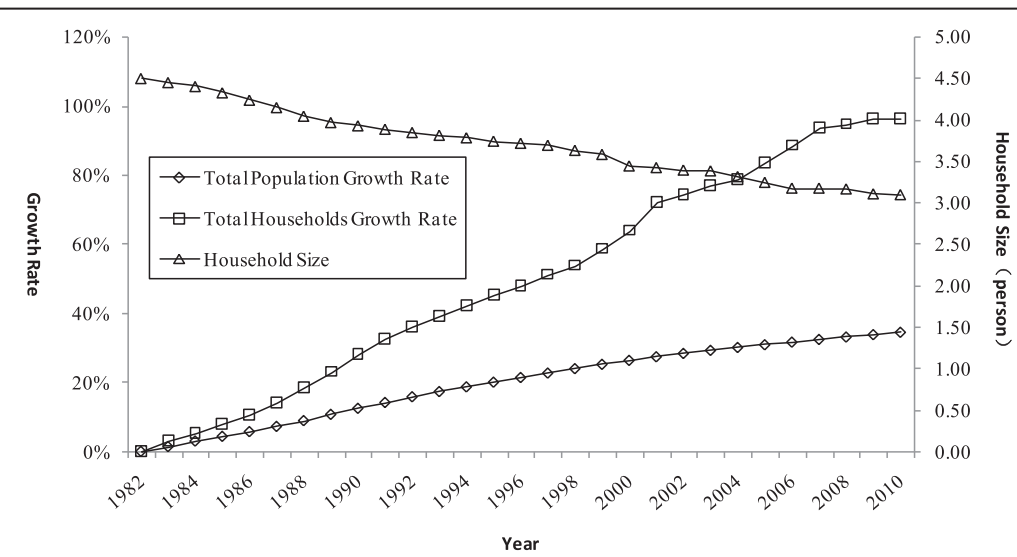

Fig. 1 Changing trends of total households and household size. Source: Based on the $6^{\text {th }}$ census 2010 and the China Population Statistics Yearbook in relevant years, published by the State Department Office of National Census \& Population and Employment Statistics Office, National Statistics Bureau (1992, 2002, 2010, 2012) 
was merely $34 \%$ in 1982, while in 2010, this number increased to $64.9 \%$ (13.7 \% were oneperson households; $24.4 \%$ were two-person households; $26.9 \%$ were three-person households), among which the two- and three-person households accounted for over half of the households. In fact, since the 1990s, the percentages of one-, two-, and three-person households continued to increase, while the percentages of the four-person, five-person, and above households continued to decrease. At the same time, as a result of population flow, the shrinkage of households in rural and urban areas was equally fast (see Table 1). In this context, the average size of Chinese households was only 3.09 persons, a decrease of 0.37 person from 2000 and 1.34 persons from 1982. This is a $30 \%$ decrease (see Fig. 1). At the same time, the number of households almost doubled.

It is not difficult to imagine the significant effect of China's family planning policies and the increasing flow of population on the changes in household size. However, by comparing the average number of 0-14-year-old children and the sizes of households between 1982-2000, studies have shown that the impact of the decline of the birth rate on household size is receding (Guo Zhigang, 2003), while the impact of the population flow on household reduction is holding strong, which drives the reduction of household size in rural areas in particular. Changes in lifestyle and people's values, in particular gender relationship and property, as well as the improvement of living conditions and environment have also definitely influenced the downsizing of households. In addition, the reduction of households is similar in both rural and urban areas. The large households that used to be common in the countryside are rapidly disappearing.

\section{Household structure simplifies while the expanded family household still accounts for a large proportion}

Household structure refers to the type and condition of residential/living units consisting of people related to each other through kinship or marriage. As a result, households can be categorized differently according to marital relationship, intergenerational relationship, kinship, and so on. In order to demonstrate a clear generational hierarchy, this paper adopts a singular generational classification. According to data from the sixth

Table 1 Changing trends in the size of Chinese households in rural and urban areas

\begin{tabular}{lccccccc}
\hline Area & Year & $\begin{array}{l}\text { 1-person } \\
\text { household } \\
(\%)\end{array}$ & $\begin{array}{l}\text { 2-person } \\
\text { household } \\
(\%)\end{array}$ & $\begin{array}{l}\text { 3-person } \\
\text { household } \\
(\%)\end{array}$ & $\begin{array}{l}\text { 4-person } \\
\text { household } \\
(\%)\end{array}$ & $\begin{array}{l}\text { 5-person and } \\
\text { over household } \\
(\%)\end{array}$ & $\begin{array}{l}\text { Average } \\
\text { household size } \\
\text { (person) }\end{array}$ \\
\hline National & 2010 & 13.66 & 24.37 & 26.86 & 17.56 & 16.66 & 3.09 \\
& 2000 & 8.30 & 17.04 & 29.95 & 22.97 & 21.73 & 3.46 \\
& 1990 & 6.27 & 11.05 & 23.73 & 25.82 & 33.13 & 3.96 \\
City & 2010 & 17.95 & 27.82 & 33.16 & 12.13 & 8.95 & 2.71 \\
& 2000 & 10.68 & 21.60 & 40.22 & 15.75 & 11.74 & 3.03 \\
& 1990 & 7.06 & 13.94 & 34.81 & 22.90 & 21.29 & 3.53 \\
Town & 2010 & 14.10 & 24.41 & 27.78 & 17.87 & 15.85 & 3.08 \\
& 2000 & 10.16 & 18.62 & 33.89 & 20.39 & 16.93 & 3.26 \\
& 1990 & 7.88 & 14.60 & 32.03 & 23.47 & 22.02 & 3.55 \\
Village & 2010 & 12.44 & 22.07 & 22.34 & 21.03 & 22.11 & 3.34 \\
& 2000 & 6.93 & 14.85 & 24.90 & 26.47 & 26.85 & 3.68 \\
& 1990 & 5.87 & 9.87 & 19.75 & 26.89 & 37.62 & 4.13 \\
\hline
\end{tabular}


census, the structure of Chinese households continued to simplify. The number of generations was declining. While the proportion of multigeneration households remained stable, the number of two-generation household dropped dramatically. At the same time, one-generation households increased substantially, showing a pattern in which the nuclear household dominates, while single-person households and expanded households supplement.

Specifically, in 2010, one-generation and two-generation households accounted for over $80 \%$ of total households. Compared with the fifth census, the percentage of twogeneration households dropped by $10 \%$, while the proportion of one-generation households increased by $11 \%$. The only-couple households and single-person households were the dominant types of one-generation households. This shows that in accordance with the continuation of low fertility, the advancement of urbanization, improvement of housing conditions, and changes in family values, an increasing number of large families split into small families. Young people are becoming more independent. At the same time, nuclear households (standard nuclear family households and impaired nuclear family households) accounted for over $80 \%$ of two-generation households. When including only-couple nuclear households in one-generation households, the proportion of nuclear family households reaches almost $60 \%$ of the total number of households (see Table 2).

Although the nuclear household has always been the dominant type of household in China, expanded households with three or more generations still account for a large

Table 2 Generational structure of Chinese households by percentage

\begin{tabular}{|c|c|c|c|c|c|c|}
\hline \multirow[t]{2}{*}{ Types of family patterns } & \multicolumn{4}{|l|}{ Sum } & \multicolumn{2}{|c|}{$\begin{array}{l}\text { Urban/rural } \\
\text { division (2010) }\end{array}$} \\
\hline & 1982 & 1990 & 2000 & 2010 & Urban & Rural \\
\hline \multicolumn{7}{|l|}{ 1-generation households } \\
\hline Single-person households & 8.00 & 6.27 & 8.30 & 13.66 & 17.03 & 11.79 \\
\hline Only-couple-households (1-generation nuclear) & 4.69 & 6.42 & 12.70 & 18.49 & 21.17 & 16.63 \\
\hline Other 1-generation households & 1.23 & 0.80 & 1.28 & 1.20 & 2.04 & 0.72 \\
\hline Sum of 1-generation households & 13.92 & 13.52 & 22.28 & 33.25 & 40.24 & 29.14 \\
\hline \multicolumn{7}{|l|}{ 2-generation households } \\
\hline Parents and unmarried children (standard nuclear) & 48.20 & 54.40 & 46.33 & 33.38 & 35.57 & 31.11 \\
\hline Single parent and unmarried children (impaired nuclear) & 4.55 & 3.58 & 2.92 & 2.70 & 2.25 & 3.16 \\
\hline Separated parent and unmarried children (impaired nuclear) & 6.96 & 4.02 & 3.15 & 3.27 & 2.71 & 3.41 \\
\hline Other 2-generation nuclear households (expanded) & 2.49 & 1.95 & 1.12 & 0.47 & 0.39 & 0.53 \\
\hline Sum of 2-generation nuclear households & 62.20 & 63.95 & 53.52 & 39.82 & 40.92 & 38.21 \\
\hline Parents and married children (2-generation lineal) & 3.82 & 3.30 & 2.34 & 3.13 & 2.85 & 3.37 \\
\hline Grandparents with grandchildren (generation-skipping) & 0.70 & 0.67 & 1.89 & 2.26 & 1.17 & 3.00 \\
\hline Other 2-generation households & 0.56 & 0.23 & 0.97 & 3.32 & 2.78 & 3.84 \\
\hline Sum of 2-generation households & 66.58 & 67.50 & 58.72 & 48.53 & 47.71 & 48.43 \\
\hline Sum of nuclear households (1- and 2-generation) & 66.89 & 70.37 & 66.22 & 58.31 & 62.09 & 54.84 \\
\hline \multicolumn{7}{|l|}{ 3-generation or above expanded households } \\
\hline 3-generation households & 16.43 & 16.48 & 16.62 & 16.50 & 11.26 & 20.27 \\
\hline Other expanded households & 2.37 & 1.82 & 2.38 & 1.62 & 0.79 & 2.16 \\
\hline Sum of expanded households & 18.80 & 18.30 & 19.00 & 18.12 & 12.05 & 22.43 \\
\hline Total & 100.00 & 100.00 & 100.00 & 100.00 & 100.00 & 100.00 \\
\hline
\end{tabular}

Source: Sampling data from 1982-2010 censuses 
proportion. In 2010, they accounted for almost $20 \%$ of total households, indicating that over $25 \%$ of the population lived in an expanded household. The percentage of expanded households with three or more generations decreased only slightly in 2010, while the percentage of three-generation households remained stable as compared with data from the three censuses between 1982 and 2000. The decrease is related to the large number of only children as well as the fact that these children are moving out of their parents' households after they find work or get married. Moreover, due to the rapid urbanization in recent years, many young people are leaving home to work and live in cities. This also contributes to the decline of expanded households with three or more generations. The fact that expanded households of three or more generations still occupy a large proportion is due to typical Asian characteristics, yet household size is much smaller than in other developing counties in Asia.

\section{Aging family households and empty-nest family households are rapidly increasing}

As the Chinese population is aging, the percentage of elderly in household population is increasing and the number of households with elderly is increasing as well. In 2010, there were more than 88 million households with elderly aged 65 and above, accounting for $21.9 \%$ of total households. Among them, about two thirds have one elderly person. However, the number of households with multiple elderly members is increasing faster than households with a single elderly. Currently, nearly 0.34 million households have three or more elderly. Moreover, in 2010 there were about 30 million elderly-only households (all members of the households are 65 years old and above). Elderly households with three or more people (younger elderly living with their parents, partners, siblings, or other members of their generation) are traditionally atypical but are starting to grow in number. These households are more common in the countryside. The elderly in cities are more likely to live in nuclear households, whereas the elderly in rural areas are more likely to live in expanded households. The percentages of elderly living alone are about the same in urban and rural areas. Compared with 2000, the number of elderly in expanded households decreased, whereas the proportion of elderly in single-person households and only-couple nuclear households grew dramatically. This shows that as the population is aging, the elderly are forming their own small families instead of living with their married children, thus contributing to the growth of singleperson families and only-couple nuclear families.

It must be pointed out that affected by factors such as household registration, housing, and population flow, the ability of the census to reflect the living conditions of the population is restricted. Still, it shows that the tendency for families to have multiple elderly persons, the co-habitation of senior and younger elderly, and the phenomena of the empty nest are becoming more acute. This will bring more challenges to the traditional family-oriented elderly care system and will impose higher standards on the society's pension system.

In addition, the increase of elderly-only households and generation-skipping households has intensified the problem of empty-nest households. In 2010, the percentage of emptynest families approached $40 \%$ of elderly households. Compared with 2000, the proportion of elderly living alone climbed to $12 \%$. At the same time, the proportion of elderly couples living alone increased steadily, surpassing $29 \%$ (including couples in which one 
was elderly). Moreover, empty-nest households with middle-aged or elderly couples accounted for more than $40 \%$ of households and surpassed $50 \%$ in urban areas. For those between the ages of 48 and 59 who were approaching their senior years, the percentage in empty-nest households was already as high as $20 \%$.

\section{Population flow is making a significant impact on changes in households}

As a result of the intensified flow of population, in particular the flow of population from the countryside to the cities, there is a huge portion of the population whose registered residence differs from their current residence under the current registration system. The sixth census shows that in 2010, the population whose registered residence differed from their current living address and had been away from their registration residence for over half a year (i.e., persons separated from their households) was as many as 261 million. This is an increase of 117 million and $81 \%$ from 2000. Among them, the number of persons who were separated from their registered residence but lived within the same city totalled 39,959,000, whereas those separated from their registered residence and living in a different city (the so-called floating population) was 221 million.

For the former category of population, the change in the family life mode is the main reason for this separation from the registered household. People who change residence for reasons of relocation, moving, seeking refuge with relatives or friends, moving to join partners, marriage, and so on account for over half of the population. For floating migrants, employment and business still constitute the primary reasons. Although some studies have shown that there is an increasing tendency for the whole household to move, the flow of labor is still the dominant factor. There is also a clear disparity between the rural and urban areas. More than $30 \%$ of rural households contribute to the population flow, whereas only $10 \%$ of urban households have members moving away. Thus, the impact of population flow on family structure is becoming apparent. Data from the sixth census also show that there is a different impact of the above disparity on the various household structures. In cities, when one person moves out, it is often the case of a grown only child leaving for education or work, whereas in the countryside, it is usually the male (husband) leaving home to work. This forces many parents in nuclear families to enter the empty-nest stage of life earlier. There is also an increase of only-couple nuclear households, impaired nuclear households, and generationskipping households as a result. Having two people moving out is more common in rural areas and is usually the result of middle-aged parents leaving together for work. The percentage of households comprised of grandparents and young grandchildren increases, as do single-person households and impaired households. The moving out of three persons occurs when young couples leave with their children. This causes an increase in single-person households and only-couple households. Most are elderly people who have lost their partners or elderly couples.

It is worth noting the rather high proportion of the floating population in urban single-person households in 2010. It is particularly prominent in first-rate cities. To a certain extent, this accelerates the simultaneous reduction of household size in urban and rural areas. First-rate cities attract an increasing number of migrants, especially young people, for their favorable economic, living, and working environment. This adds to the formation of single-person households. Taking Shanghai as an example, in 2010, 
there are 1,422,700 single-person households, accounting for $17.2 \%$ of all households. This is an increase of $3.8 \%$ from 2000. Among these people, $60.1 \%$ were migrants. If we look at the age groups, about $80 \%$ of the population between 15 and 44 years old in single-person households were migrants. The percentages are particularly high for the age groups of 15 to 19,20 to 24 , and 25 to 29 , accounting for $92.9,90.2$, and $77 \%$ respectively (see Fig. 2). Migrants in Shanghai also predominantly fall into these three age groups.

In general, the stability of an extremely low birth rate, dramatic population flow, rapidly aging population, and improvement of housing conditions are the main factors behind the changes in Chinese households. As the reform of family planning policies deepen and housing policies continue to improve, the impact of population flow and the aging population on the changes in households will become more prominent.

\section{Characteristics of changes in various different types of households}

\section{Single-person household}

In 2010, the proportion of single-person households reached $13.7 \%$ and was becoming a noticeable type of household. Figure 3 shows a low percentage of members of singleperson households aged between 0 and 19. These people have not reached adulthood and are not able to live independently. This kind of household is probably related to the population flow and the "purchasing/residing strategy" of some families. There is a clear difference between heads of household above 20 years old in rural and urban areas. In cities, these people are predominantly young people, in particular males of the 25 to 34 age group. This is due to the fact that in cities, there are more single young men of this age than women, as well as the fact that young people are more likely to purchase property and live independently in the cities. In the rural areas, single-person households mainly consist of left-behind elderly above 55 years old. This indicates that the migration of young people from the countryside to the cities has left behind a large number of empty-nest or even single-elderly families. Moreover, there are more women as the sole members of the household than men. This is due to the fact that women normally live longer than men and are more likely to lose their partners when they grow old. Thus, the need for elderly care in the rural areas will surge.

Data from the censuses between 1990 and 2010 show that the proportion of singleperson households grew by $2 \%$ during 1990-2000 and 5.4 \% during 2000-2010. In

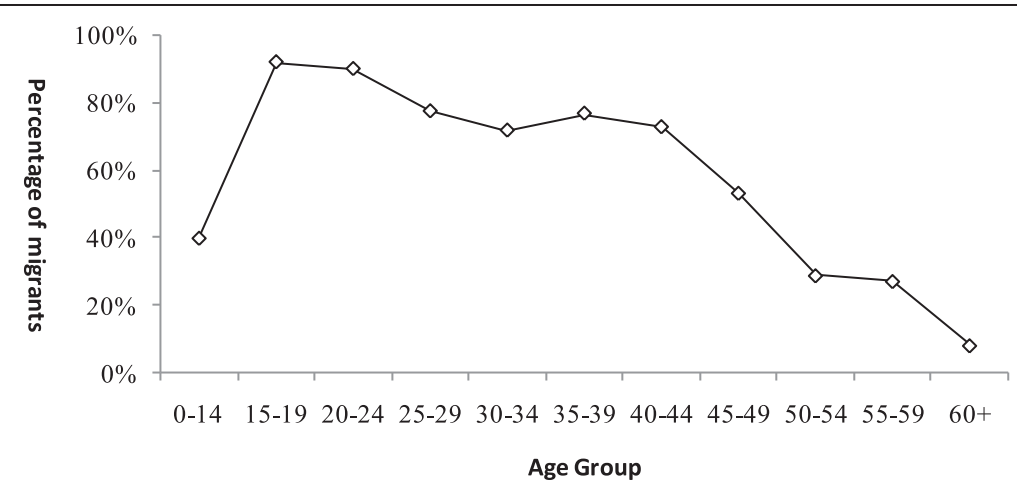

Fig. 2 Percentage of migrants in single-person households by age group in Shanghai, 2010. Source: Sampling data from Shanghai census, 2010 

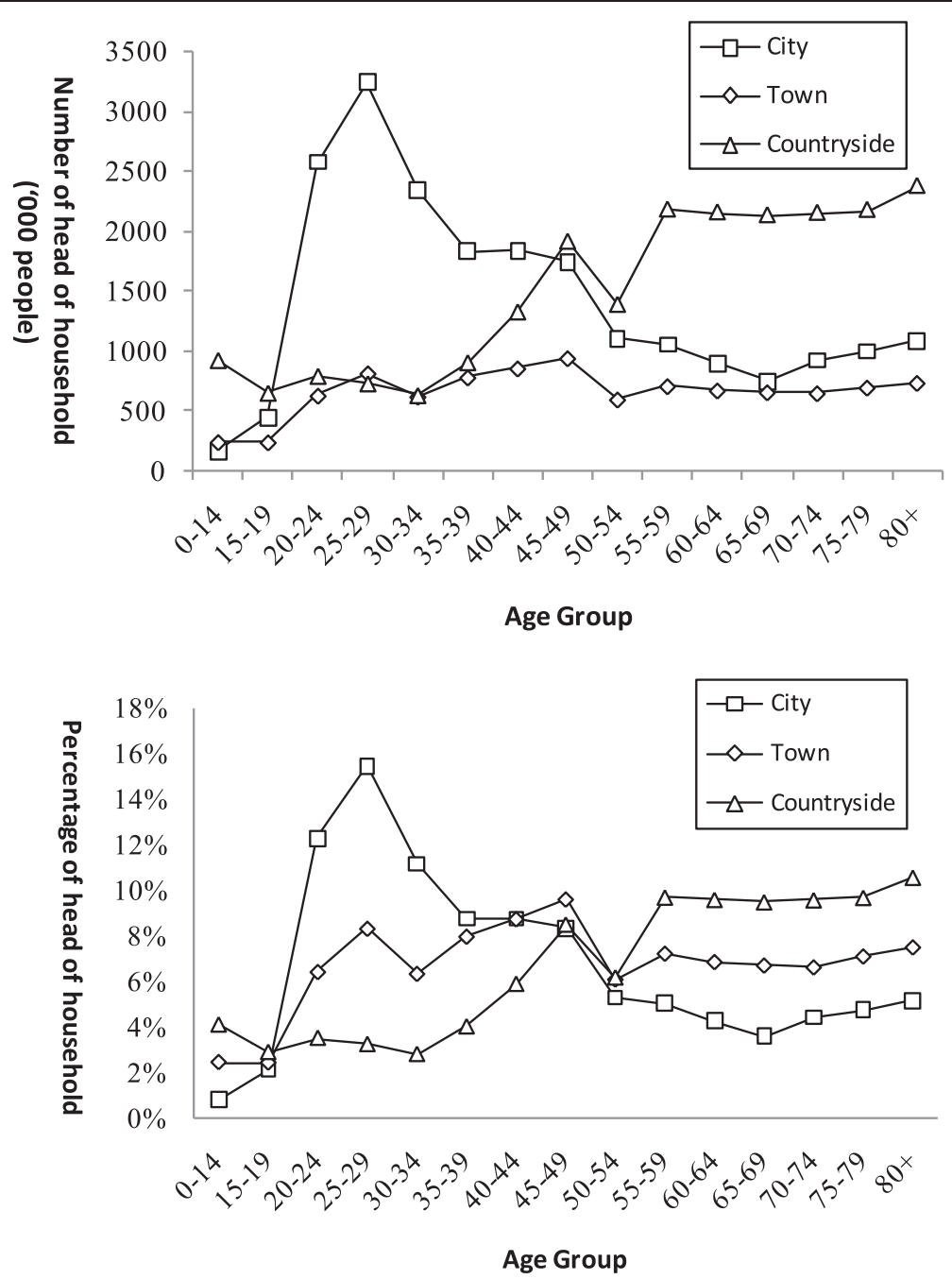

Fig. 3 Age groups of single-person households in 2010. Source: Sampling data from Shanghai census, 2010

2000 , the number of single-person households increased in the fifth census mainly because the average age of first marriage of young people leaving their parents to live independently increased. With the rise of the divorce rate, divorced parents who do not live with their children also contributed to the growth of single-person households. Compared with the fifth census, the increased rate of single-person households was higher in 2010. Besides the delay of first marriage and the increase in the divorce rate, the improvement of housing conditions, the population flow, and the expanded proportion of widowed elderly resulting from the prolongation of expected life span are also important factors.

Although the number and percentage of single-person households are growing in China, the percentage is still much lower in comparison with developed Western countries. Taking the USA as an example, the percentage of single-person households within the same period of time is almost three times that of China. Two reasons may contribute to this difference. First, there are relatively fewer people who never marry in China; second, the proportion of elderly, especially the widowed, who live alone is lower in China than in developed Western countries. 


\section{The nuclear family household}

The percentages of nuclear family households (one-generation and two-generation nuclear households) in China were 66.9, 70.4, 66.2, and $58.3 \%$ in 1982, 1990, 2000, and 2010, respectively. Although there is a clear tendency toward decreasing, the nuclear family is still the dominant type of household in China. Data from the sixth census shows that only-couple nuclear households are the fastest growing, whereas the twogeneration standard nuclear households are decreasing most rapidly.

Specifically, in 2010, the percentage of only-couple nuclear households among all households was 18.5 \%, 5.8 \% higher than in 2000, 2.88 times the number in 1990, and 3.94 times the number in 1982. It is the fastest-growing type. From Fig. 4, we can see that only-couple nuclear households of the 45 to 70 age group in both rural and urban areas are the most prevalent type. The changes in only-couple nuclear households were more marked in rural areas than in urban areas, as age increases. In the countryside, the number
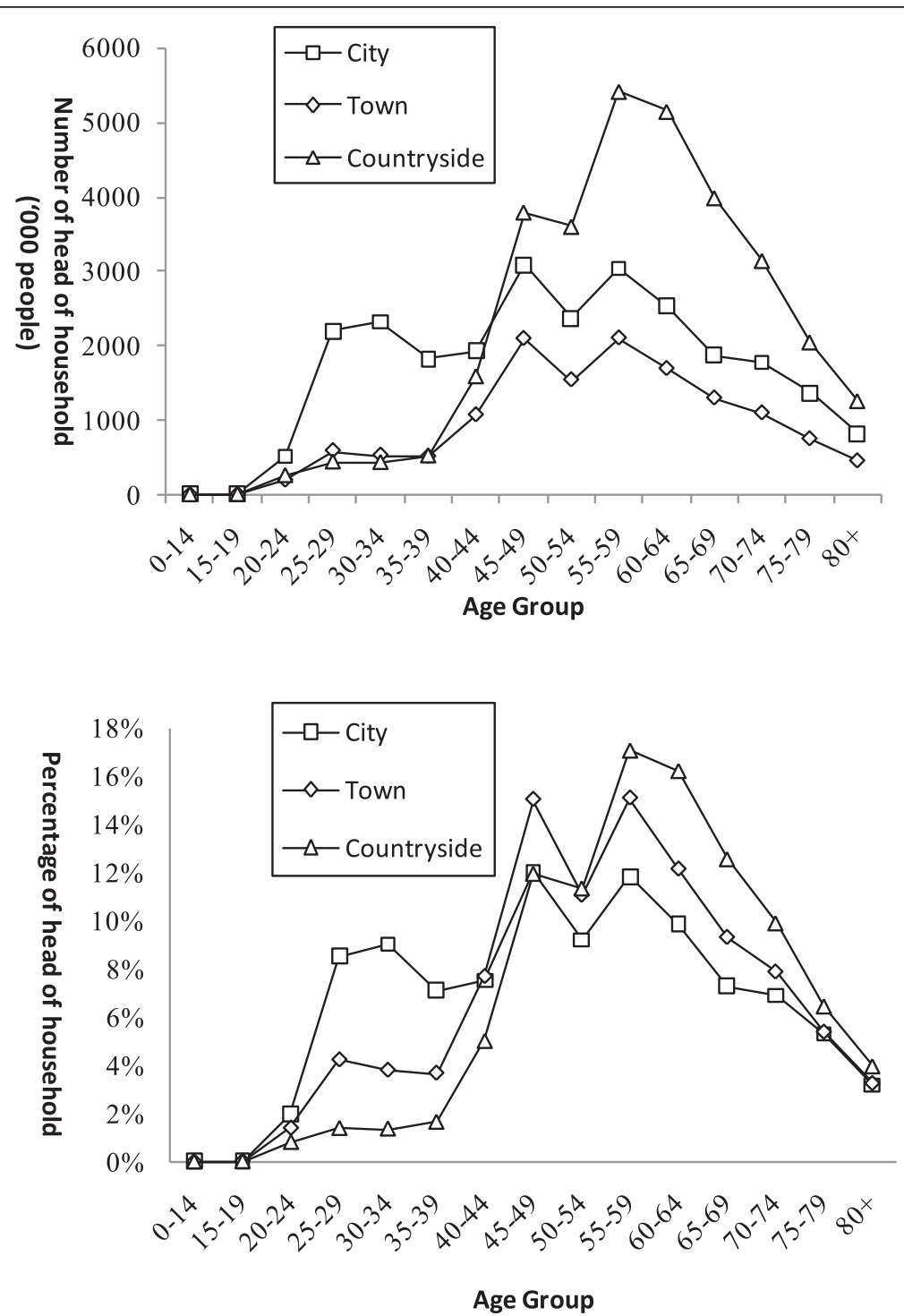

Fig. 4 Age group distribution of only-couple nuclear households. Source: Based on calculation of sampling data from 2010 census 
of only-couple households of the 45-49 age group is significantly larger than in cities, whereas the number of only-couple households of the 20 to 44 age group is smaller than in cities. In cities, the number of only-couple households of the 25 to 39 age group is larger than in the countryside. This demonstrates the fact that as young laborers from the countryside migrate to the cities, their elderly parents are left behind in the villages. This leads to the double peaks of young-couple nuclear households in the city and middle-aged and elderly couple nuclear households in the countryside. Moreover, the high rate of late childbirth and the growing number of DINK families and couples who are not able to have children all possibly contribute to the peak of nuclear households aged 25 to 39 in urban areas.

In 2010, the percentage of two-generation nuclear households was $39.8 \%$. This is a large decrease from 2000 and 1990 (Fig. 5). Statistically speaking, the reason for the decrease in two-generation households since the fifth census is mainly due to the significant increase of single-person and only-couple nuclear households.

Among them, the standard nuclear household constitutes the majority of two-generation households, accounting for 33.4\% of all households in 2010. In 2000 and 1990, the percentages were 46.3 and $54.4 \%$, respectively. The standard nuclear household was the fastest decreasing household type; its percentages dropped continuously over the past two decades. If we look at the age distribution of the head of standard nuclear households (see Fig. 6), there is little difference between rural and urban households. Both show an almost normal distribution, peaking at the 40 to 44 age group. The children of this group are school age and do not require care from their grandparents. The decrease in the age group of 50 years old and above is due to the fact that their children have either reached adulthood or married. This situation turns the standard nuclear household into an only-couple nuclear household or two-generation lineal household.

In 2010, the proportion of impaired nuclear households remained stable. On the one hand, the percentage of single-parent nuclear households was $2.7 \%$, lower than $4.6 \%$ in 1982, $3.6 \%$ in 1990, and $2.9 \%$ in 2000. As the divorce rate climbs and due to the fact that people divorce at a younger age in the city, many divorced couples have no children or their children have left home. In addition, the high rate of remarriage and low rate of divorced people staying single lead to the percentage of single-parent household continuing to abate. Moreover, the percentage of separated nuclear households was $3.3 \%$, compared to $7.0 \%$ in 1982, $4.0 \%$ in 1990, and $3.2 \%$ in 2000. Existing research shows that the main

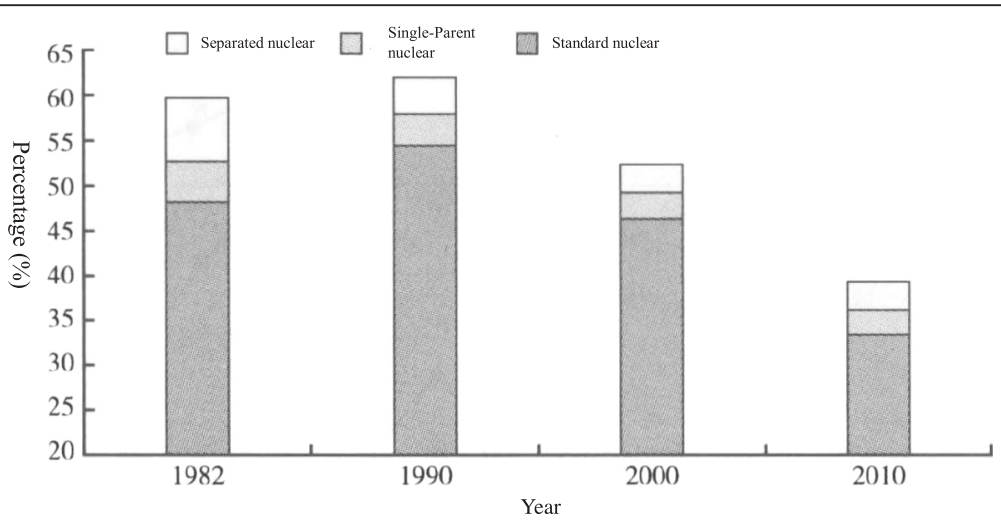

Fig. 5 Changes in percentage of two-generation nuclear households, 1982-2010. Source: Sampling data from censuses 1982-2010 

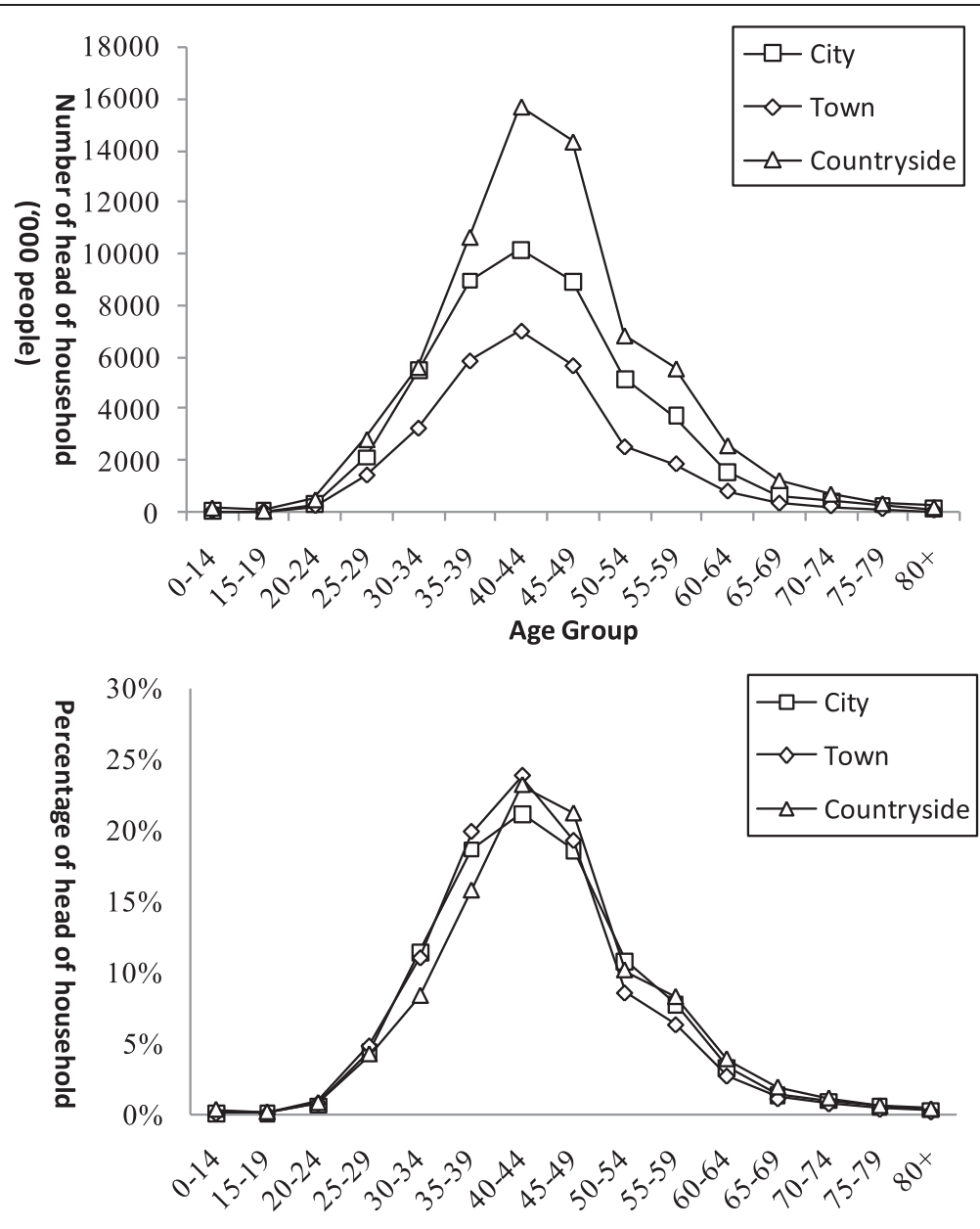

Age Group

Fig. 6 Distribution of age groups of standard nuclear households change "head of household" to "heads of households" in both graphs. Source: Sampling data from 2010 census

reason for Chinese couples to live apart is their jobs. Censuses in 1982-2010 show that the head of a separated nuclear household is usually female. China's registration system is the main reason behind this phenomenon. Usually, the father of the separated nuclear household works in the city/town, while the mother lives with the children. It takes many years for the father to obtain permanent residence in the city and be able to transfer his partner and children into the same household. This is still not uncommon, but the proportion of separated households has drastically decreased during 2000-2010. This may be due to the urban setting's reduced level of difficulty of obtaining a residence permit for the purpose of reuniting the family.

It is worth noting that although statistically speaking the nuclear household has been the main type of the Chinese household and many scholars are claiming that Chinese families have been nuclearized, in fact at a microlevel many family functions are still performed by the network of relatives, in particular the parents (e.g., taking care of grandparents) due to the lack of social security. The Blue Book of Chinese Society published in 2007 lists 14 channels from which people seek help when facing difficulties in 
life. Data show that "family" and "kin, clan" are the top two choices (Chinese Academy of Social Sciences, 2007).

\section{Three-generation households}

In 2010, the percentage of three-generation households was $16.5 \%$. In fact, the percentages of three-generation households remained rather stable, between 16.4 and $16.7 \%$ during the four censuses in 1982, 1990, 2000, and 2010. It was the most stable type of household. From a traditional perspective, the three-generation household normally consists of the elderly, the middle aged, and the young (or the elderly, the young, and the children). It has the functions of both elderly care and childcare and constitutes a critical household type when social security is not well established. Yet, today's threegeneration household differs from the traditional form. The key difference is that they "live together but do not share wealth." This is particularly typical in urban areas since the parent generation and child generation each control their own income. However, they still live together and are therefore able to take care of and help each other. This mode keeps family conflict at a relatively low level. Since the two generations of couples have certain common interests, they discover the advantages and basis for their cooperative life (Wang Yuesheng, 2006).

Although the percentages remained stable, three-generation households between 1982 and 2010 differed considerably in terms of age composition. In 1982, the peak age of the head of household in a rural area was 30 years old, compared to 45 to 60 years old in an urban area. This relates to the housing distribution system in cities. During 1990-2000, the age distribution of the heads of households in rural areas had double peaks at 30 and 50 years old, while the peak moved to 60 to 65 years old in cities. In 2010, the peak in cities was 55 years old, and there was another peak at 40 years old in rural areas. The two seemed to be merging. It is not difficult to discern that while the head of the household in a city is usually middle aged between 45 and 65 or at a lower senior age, the head of the household in rural area changed from young people to middle-aged or elderly people. This is due to the transformation of the economic pattern in the countryside. In 1982, the rural economy was still imprinted with the characteristics of the collective economy; thus, the heads of households were normally young people who made up the main labor force. As a result of urbanization and the development of the market economy, the distribution of the heads of households is becoming isomorphic to their counterparts in the city.

The percentages of expanded households with three generations or more were 18.1, $19.0,18.3$, and $18.8 \%$. These percentages remain relatively stable during the four censuses. There was only one apparent surge during 1990-2000. Zeng Yi and others (Zeng, 1986; Zeng Yi aand Wang Zhenglian, 2005) explain this surge as the delayed effect of the family planning policy, thus rejecting the argument that Chinese families are returning to tradition. Data from the sixth census confirms Zeng's judgment. When the delayed effect passed, the number of households with three or more generations again reduced. The trend for Chinese families to downsize is irreversible.

\section{A few special types of households}

The sixth census in 2010 further demonstrated the diversification of Chinese households. A large number of nontraditional households emerged, especially the elderly-only 
household (in particular the two-generation elderly-only household and multiple-member elderly-only household), the generation-skipping household, elder single-person household, single-parent household, DINK family household, and the left-behind household resulting from the population flow. Due to limitation of space, this paper only briefly addresses the elderly-only household, generation-skipping household, and DINK household.

The term "elderly-only household" refers to a household consisting of only elderly people. As the aging of China's population intensifies, the elderly-only household is drawing much attention from society and has become one of the focuses of future family policies in China. Data from the sixth census show that there are about 30 million elderly-only households with elderly aged 65 and above. They form $8.1 \%$ of total households. Among these households, $27.1 \%$ are in cities, $17.7 \%$ are in towns, and $55.2 \%$ are in rural areas. In terms of age distribution, in both rural and urban areas, the peak is the 70 to 74 age group. Still, $32.8 \%$ of the heads of households in the countryside are still working, whereas only $4.1 \%$ of their urban counterparts are employed. Migrant workers from rural areas are usually young and middle-aged people, and many of their left-behind parents are still farming.

Two types of the elderly-only household are worth further attention. One is the twogeneration elderly-only household consisting of younger elderly and senior elderly (normally the younger elderly are living with their parents). The other is the one-generation elderly-only household consisting of elderly living with their siblings. These elderly usually have no children or children who work far away. These elderly deserve special attention. There are 149, 000 one-generation elderly-only households composed of elderly living with their siblings, 108,000 of which live in the countryside. There are another 36,000 one-generation elderly-only households consisting of three or more people, 28,000 of which live in the countryside. In this case, the elderly are living with their partners and siblings. This has become an acute problem in rural areas.

The traditional model of elderly care is developing in new forms. When the resources devoted to reproduction are no longer later converted into elderly care when needed, the elderly, not sufficiently protected by social security, choose to rely on help and care from their partners, siblings, or even parents. When a mature social security system is absent, the Chinese family is forced to utilize any resource it has to protect its members from risk. However, given the continued decrease of the birth rate, the acceleration of aging in the population and the intensified population flow, the number of elderly-only families is rapidly increasing, and they are finding it more challenging to defend themselves against structural pressure during China's reforms. This demands specific attention in the formation of future family policies.

A "generation-skipping household" refers to households consisting of grandparents and grandchildren, with one generation missing in between. In 2010, the percentage of such households was $2.26 \%$, an increase of $0.37 \%$ from 2000. It was also 3.37 times as many as in 1990 and 3.23 times as many as in 1982. Among these households, $16.6 \%$ were in cities, $32.1 \%$ were in towns, and $51.2 \%$ were in rural areas. This indicates that it was very common for a young couple to leave the countryside and work in the city, while leaving their children behind with their grandparents. Although these households should be counted as two-generation households in terms of their format, from the perspective of generation difference, they are closer to three-generation households. Although the inbetween generation does not live with the other two, the economic interaction among these generations is often frequent (regularly sending money back home and so on). The 
couples also frequently visit their parents and children back home and to a certain extent fulfill the responsibilities of childcare and elderly care. Since the couples often travel to the southern and eastern parts of the nation where the economy is more developed and can thus earn a much higher income, their ability to fulfill their family obligation-particularly their economic ability to take care of their children and parents-is strengthened.

It is worth pointing out that the generation-skipping household in rural areas and some of the elderly-only households (i.e., only parents are left behind) are forced residence arrangements that may be temporary. As the new model of urbanization pushes forward, the rural-urban development become more balanced, and the policy of residence registration undergoes reform, the problems that come with the generationskipping household are likely to be assuaged.

The four censuses of 1982-2010 all show that the number of only-couple nuclear households is rapidly growing. This is due to the fact that more middle-aged and elderly couples are no longer living with their grown-up children, and more young couples are delaying childbearing. Furthermore, some young and middle-aged couples are not having children at all. This results in a large quantity of double income no kids (DINK) households. There is no clear definition of a DINK household from a demographic or sociological perspective. The couple in a DINK household "are able to procreate, but actively choose not to, or forced not to out of subjective or objective reasons." ${ }^{11}$ Thus, it cannot be defined simply by whether one has children. According to the preliminary results of a 2013 study carried out by Fudan University on the social transformation in the Yangtze Delta area and targeting the generation born in the 1980s, $4 \%$ of young people aged 24 to 27 are not planning to have children. The rate drops quickly to $2.4 \%$ for the age group 29 to 32 . This indicates an unstable inclination toward childbearing among young people. As time passes, "young" DINK households may quickly transform into standard nuclear households and thus no longer belong to the DINK category. Thus, the author chose only-couple households aged 35 to 49 in urban areas as the target population. They have a relatively stable inclination toward childbearing, although their ability to have children has been weakened. Although this may be a rather narrow definition for a DINK household, the sixth census shows there were still as many as 411,000 DINK households in 2010, several times greater than 20 years ago.

\section{Residence models of elderly households}

As the Chinese population ages, households that have elderly people increase as well. By 2010, over one fifth of households contained at least one elderly aged 65 or above. At the same time, coverage and support from the national pension system is rather limited. This means that when the elderly are no longer employed, they have to rely on their savings or help from other family members. Moreover, the senior elderly needs a great deal of daily care. So far, their family members are directly or indirectly providing such care. Against this backdrop, identifying residence models of the elderly and their changing pattern will lay the foundation for making future family planning and pension policies.

Data from the sixth census reveal information about the elderly's residence model. For elderly aged 65 and above, it is still very common for them-about $57 \%$-to live with their children, including grandchildren. The percentage of elderly in this age group increased dramatically to $41 \%$ and above. In comparison, the percentage of elderly aged 80 
and above who live alone grew even faster, exceeding $34 \%$. These senior elderly who live alone account for $17.5 \%$ (see Table 3 ). The ratio of the elderly family in one-generation, two-generation, and expanded households is 4:2:4, showing a dumbbell distribution.

\section{A significant decrease in percentage of the elderly living with their children, especially the senior elderly}

In China, generational support from within the family is still the main source of security and care for the elderly. Most elderly live with their children, including grandchildren. In 1990, the percentage of elderly 65 and above living with their children was similar to 1982. However, in 2000 and 2010, the percentage dropped by 10 and $5 \%$, respectively. From 2000 to 2010 the percentage of elderly aged 80 and above who lived with their offspring decreased from 76.8 to $63.8 \%$. While this is a drastic $13 \%$ drop, the percentage in 2000 is similar to that of 1982 and 1990. One of the reasons may be that relatively young and healthy elderly or elderly couples prefer to live by themselves. Data from the sixth census show that more than $90 \%$ of elderly aged 65 to 79 were basically healthy and capable of taking care of themselves. This enables them to rely less on care from their children. The other reason may be that their children move away for purposes of marriage or employment.

Moreover, data from the sixth census reveal that over $70 \%$ of the heads of households are the children of the elderly when a single elderly is living with their offspring. This is particularly dominant in rural areas. Households that have an elderly head account for only $7.35 \%$. For standard nuclear households and two-generation lineal households that contain elderly people, only $23.4 \%$ of the heads of households are the children of the elderly. Yet, this is much higher a proportion than 20 years ago. Although the choice of the head of household is often rather random or made out of practical considerations, this may still indicate the weakening position of the elderly in the household, especially for the single elderly. Abundant case studies and surveys have pointed out that the abating authority of the elderly in the family does not seem to affect the model of elderly care in modern China. From a macro perspective, even if

Table 3 Residence models of elderly in 2010 by percentage

\begin{tabular}{|c|c|c|c|c|c|c|}
\hline \multirow[t]{2}{*}{ Residence models } & \multirow{2}{*}{$\begin{array}{l}1982 \\
65+\end{array}$} & \multirow{2}{*}{$\begin{array}{l}1990 \\
65+\end{array}$} & \multicolumn{2}{|l|}{2000} & \multicolumn{2}{|l|}{2010} \\
\hline & & & $65+$ & $80+$ & $65+$ & $80+$ \\
\hline Elderly living alone & 12.2 & 9.6 & 9.6 & 12.4 & 12.5 & 17.5 \\
\hline Elderly couple (1-generation nuclear) & 13.7 & 17.1 & 23.9 & 11.2 & 29.2 & 16.8 \\
\hline Elderly couple and unmarried children (standard nuclear) & 6.9 & 6.6 & 5 & 1.7 & 3.6 & 1.7 \\
\hline Single elderly and unmarried children (impaired nuclear) & 4.6 & 3.8 & 3.1 & 4.6 & 2.3 & 3.1 \\
\hline Other 2-generation nuclear (expanded nuclear, etc.) & 3.4 & 2.7 & 2.3 & 2.1 & 2.8 & 2.0 \\
\hline Elderly and married children (2-generation lineal) & 3.5 & 3.7 & 5.2 & 12.3 & 6.9 & 13.6 \\
\hline Elderly and grandchildren (generation-skipping) & 3.8 & 3.7 & 5.2 & 6.2 & 5.6 & 5.0 \\
\hline Elderly, children and grandchildren (3-generation lineal) & 47.2 & 47.4 & 41.1 & 38.0 & 32.8 & 30.0 \\
\hline Other expanded household & 3.8 & 4.8 & 3.6 & 10.9 & 3.2 & 8.4 \\
\hline Sum of single elderly and elderly couple households & 25.9 & 26.7 & 33.5 & 23.6 & 41.7 & 34.3 \\
\hline Sum of elderly living with children & 73.2 & 72.7 & 62.2 & 75.8 & 57.2 & 63.8 \\
\hline
\end{tabular}

"65+" refers to age 65 and above; " $80+$ " refers to age 80 and above. Source: sampling data from 1982-2010 censuses. "Elderly couple" refers to couples in which both are elderly people, as well as couples with one elderly person 
the elderly do not live with their children their interaction is frequent (Whyte, 2005). However, from a micro perspective, this interaction is becoming more haphazard, to such an extent that basic interaction among generations such as visiting one's parents has to be enforced by law. Cases of ignoring the needs of the elderly or elderly abuse are not rare (Peng and $\mathrm{Hu}, 2011$ ).

An increasing percentage of elderly living alone, while the residence model of "co-habitation of multiple generations" no longer dominates

Although living with their children is still the major model of residence for the elderly, the percentage of this model has continued to decrease over the past 20 years. In 2000, the percentage of three- or-four-generation co-habitation dropped below $50 \%$ for the first time and further decreased to $40 \%$ in 2010 . At the same time, the percentage of elderly living independently experienced sustained growth, exceeding $40 \%$ in 2010 . There was a $72.3 \%$ increase of the proportion of elderly couple households from 1990 to 2010, making it the fastest-growing type of residence model for the elderly. More elderly people prefer to live independently, and additionally, the migration of their children contributes to the decrease of the percentage of co-habitation with their parents. In general, the residence model of living by oneself is joining the traditional model of cohabitating with offspring as the two most common models of residence for the elderly.

Moreover, the residence model of elderly aged 80 and above has a few unique features. Currently, the age of 80 is above the average life expectancy in China. This causes many cases of bereavement. As a result, the percentage of senior elderly couple living together is much lower than that of younger elderly couples. Furthermore, the percentage of senior elderly living alone was much higher than the younger elderly in both 2000 and 2010. Compared with younger elderly households, a considerable number of senior elderly are in poor health. Without care from their children or partners, they are more likely to become the "forgotten" social group. These elderly are most in need of attention from society. The prevalence of "living-alone" elderly is the result of a combination of factors. One is that the improvement of living conditions makes it possible for the elderly to live independently; another is that under the only-child policy family size is shrinking. At the same time, population flow encourages the children of these families to study or work away from home. Elderly living alone is no longer a personal or family issue; it is an urgent social policy problem that must be resolved.

\section{Gender and rural-urban differences in residence models of the elderly}

Data show that female elderly are more likely to live with their children than male elderly, and this difference has become more apparent since 2000. This is because females are expected to live longer and thus more likely to lose their partner. The percentage of elderly females living alone is also increasing due to the high rate of bereavement. A large number of female elderly are also more economic dependent than their male counterparts. On the other hand, it is also possible that they are living with their married children to care for their grandchildren.

In both urban and rural areas, the most common types of residence model of elderly people involve living independently or living with their married children and grandchildren. Relatively speaking, elderly in urban areas are more likely to live independently or 
live in nuclear families. The increasing number of elderly living alone requires that much more social wealth and public resources be put into the domain of elderly care. The existing pension and service systems in China are facing enormous challenges. As the model of Chinese households changes and the aging process of the population accelerates, the provision of service and care for the elderly is no longer a family business but a problem demanding the participation of all parties in society. However, the Chinese society is not prepared. By 2009, there were 38,060 elderly care institutions with 2.662 million beds, capable of serving only $1.5 \%$ of the elderly population nationwide. This rate is far below the standard 5 to $7 \%$ in developed countries. It is also lower than the rate of 2 to $3 \%$ in developing countries such as Brazil and Romania (Zhang, 2010). At the same time, the number of "incapable" elderly reached 14 million and is expected to reach 38 million after 2050 (Dai, 2011). This demonstrates the imbalance in the supply and demand of elderly care in China. It is therefore an urgent task to establish a variety of balanced service systems in addition to elderly care at home in both rural and urban areas. The supply of elderly services must be increased while regulating public service spending to a reasonable scale.

\section{Discussion}

China is experiencing a double transformation in demography and family patterns. The rapid and drastic change in demography has intensified the changes in households. With regard to the demographic system itself, the main factors for its transformation is the stability of the extremely low birth rate, the rapidly aging population, the dramatic population flow, and the improvement in housing conditions. The changes of household quantity, size, structure, and residence model all occurred under an environment in which families have only few children or one child. At the same time, the aging of the population is normalizing. Moreover, although the geographic separation of family members resulting from the population flow has not weakened economic interactions between family members, their support for each other in daily life has definitely been restricted.

In addition, the changes in households are also accompanied by larger social transformations. Social transformation has remolded the family relationship and its function. The power dynamics between parents and children, and husband and wife are also undergoing change. The transference of cultural and traditional values between generations is weakening. A small family struggles to carry out the duties of child rearing, elderly care, and domestic labor. Chinese families are becoming smaller but not necessarily more "nuclear." As the danwei system falls apart, individuals are now "members of a family" instead of "members of the unit." Besides some of the function carried out by the state, the major part of caregiving services is still performed by the family. The traditional mutual support system is still the prerequisite and basic form for coping with outside risks. The Internetbased family relationship is emerging. To a certain extent, this may strengthen links between family members, but it also suffers from an extremely high level of fragility when mutual support within the family encounters difficulties.

Unlike in Western countries, the Chinese family is not only an economic unit for production and reproduction, it is also the basic unit of order, education, and welfare. It is endowed with the responsibility to socialize and protect its members. During the process of demographic and social reforms, the state imposes mandatory intervention into family patterns out of its own necessity and manipulates the family relationship and functions 
based on utilitarian principles (Yang, 2011a). Family thus becomes merely a tool at the policy level. At the same time, there is no efficient policy or necessary institutional environment to support the innate development of the family. In the absence of mature institutions, although the tradition of being family-centered and the isomorphism of family and nation is doing everything possible to support family members and help them resist risks, the family is finding it increasingly challenging to cope with the structural assault from the multiple transformations of demography, family, and society. As China's society and economy further develops, the changes in demographic structure, social environment, the family model, and people's living conditions will bring more significant challenges to social stability and the various social policies that ensure the normal function of society. Improving family policies and reforms will be a key issue for China.

\section{Endnote}

${ }^{1}$ See Wiki Baidu for the definition of "DINK family" (http://baike.baidu.com/link? url = 2HMR - CXBIsfkICVmFC7Tn8n5ahbwOJbpxt_w6If2oWbq2Bk38USH5PkMapwd_SEul zztVN6vuJmgNb2tywupaa), 9 March 2014.

\section{Competing interests}

The authors declare that they have no competing interests.

\section{Acknowledgements}

This work has been in part supported by Grant 11CRK008 from the National Social Science Foundation and Grant 71391330149 from the National Natural Science Foundation State Department Office of China. ZH and XP carried out the data analysis and processing, participated the sequence alignment and drafted the manuscripit. Both authors read and approval the final manuscript.

\section{Author details}

${ }^{1}$ School for Social Development and Public Policy, Fudan University, Shanghai, China. ${ }^{2}$ Center for Population and Development Policy, Fudan University, Shanghai, China.

Received: 7 July 2015 Accepted: 2 September 2015

Published online: 21 September 2015

\section{References}

Chen, W, and S Yang. 2011. Experiences and lessons from the 6th census. Population Research 6: 19-31.

Dai, W. 2011. Analysis of the needs of long-term care for elderly and its impact factors. Population Research 4: 86-94. Fei, HT. 1933. Peasant life in China, 37-42. London: Routledge and Kegan Paul Ltd.

Feng, X. 2009. Family structure of the parents of the first generation of the only child. Social Science Research 2: 104-110. Guo, Z. 2003. Household changes in 1990s in China, 280-289. Beijing: Paper presented at the 2000 National Census Science Conference.

Guo, Z. 2008. Discussion and analysis of changes of Chinese households. Chinese Journal of Population Science 3: 2-10. Institute of Sociology, Chinese Academy of Social Science. 2007. Blue book of Chinese society, 20-50. Beijing: Social Science Academic Press.

Ma, C, Li, Y, Tang, C, Wang, Z, and J Shi. 2011. Changes of Chinese urban families during reforms, 292-305. Beijing: Social Science Academic Press.

Peng, $X$, and Z Hu. 2011. China's population aging from the perspective of public policy. Social Sciences in China 3: 121-138.

State Department Office of National Census \& Population and Employment Statistics Office, National Statistics Bureau. 1992. Data of the 4th national census in 1990, 496-529. Beijing: China Statistics Press.

State Department Office of National Census \& Population and Employment Statistics Office, National Statistics Bureau. 2002. Data of the 5th national census in 2000,643-660. Beijing: China Statistics Press.

State Department Office of National Census \& Population and Employment Statistics Office, National Statistics Bureau. 2012. Data of the 6th national census in 2010, 345-389. Beijing: China Statistics Press.

State Department Office of The Sixth National Census \& Population and Employment Statistics Office, National Statistics Bureau. 2011. Major statistics of the 6th national census in 2010, 3-8. Beijing: China Statistics Press.

Tang, C. 2012. Family relationships in Chinese cities. Social Sciences in Jiangsu 2: 92-103.

Wang, Y. 2006. Analysis of the structural changes of the contemporary Chinese families. Social Sciences in China 11: 96-108.

Whyte, MK. 2005. Continuity and change in urban Chinese family life. The China Journal 53: 9-33.

Yang, D. 2011a. Focusing on changes of the Chinese families; discussing public policies to support families. Women Studies 6: 89-94.

Yang, S. 2011b. Changes of contemporary Chinese families and family solidarity. Journal of Peking University (Philosophy and Social Science Edition) 2: 150-158.

Zeng, Y. 1986. Changes in family structure in China: a simulation study. Population and Development Review 12: 675-703. 
Zeng, Y, and Z Wang. 2005. Changes of Chinese families and residence patterns for elderly from 2000 census. In Papers at the international conference on China's 2000 census, ed. State Department Office of National Census \& Population and Employment Statistics Office, 463-475. Beijing: China Statistics Press.

Zhang, K. 2010. Reflections on aging population studies, 19-38. Shanghai: Paper presented at the Shanghai Forum: Facing Challenges from the Aging Society.

Zhu, Q. 2012. Predicting China's birth rate, 2000-2010: preliminary study of data from 6th census. Chinese Journal of Population Science 4: 68-77.

\section{Submit your manuscript to a SpringerOpen ${ }^{\circ}$ journal and benefit from:}

- Convenient online submission

- Rigorous peer review

- Immediate publication on acceptance

- Open access: articles freely available online

- High visibility within the field

- Retaining the copyright to your article

Submit your next manuscript at $>$ springeropen.com 